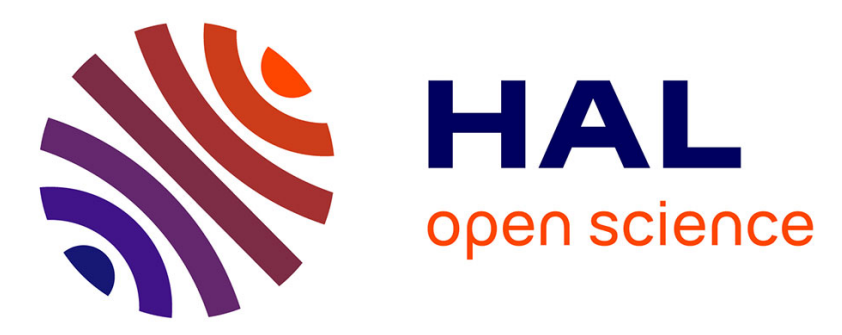

\title{
The Performance and Preference of Different Fingers and Chords for Pointing, Dragging, and Object Transformation
}

\author{
Alix Goguey, Mathieu Nancel, Géry Casiez, Daniel Vogel
}

\section{To cite this version:}

Alix Goguey, Mathieu Nancel, Géry Casiez, Daniel Vogel. The Performance and Preference of Different Fingers and Chords for Pointing, Dragging, and Object Transformation. In Proceedings of CHI'16, the 34th Conference on Human Factors in Computing Systems, May 2016, San Jose, United States. pp.4250-4261, 10.1145/2858036.2858194 . hal-01267607

\section{HAL Id: hal-01267607 https://hal.inria.fr/hal-01267607}

Submitted on 8 Oct 2020

HAL is a multi-disciplinary open access archive for the deposit and dissemination of scientific research documents, whether they are published or not. The documents may come from teaching and research institutions in France or abroad, or from public or private research centers.
L'archive ouverte pluridisciplinaire HAL, est destinée au dépôt et à la diffusion de documents scientifiques de niveau recherche, publiés ou non, émanant des établissements d'enseignement et de recherche français ou étrangers, des laboratoires publics ou privés. 


\title{
The Performance and Preference of Different Fingers and Chords for Pointing, Dragging, and Object Transformation
}

\author{
Alix Goguey ${ }^{1}$, Mathieu Nancel ${ }^{2}$, Géry Casiez $^{3}$, Daniel Vogel ${ }^{2}$ \\ ${ }^{1}$ Inria Lille, France, ${ }^{2}$ University of Waterloo, Canada, ${ }^{3}$ Universit de Lille, France \\ alix.goguey@inria.fr, \{mnancel,dvogel\}@uwaterloo.ca, gery.casiez@univ-lille1.fr
}

\begin{abstract}
The development of robust methods to identify which finger is causing each touch point, called "finger identification," will open up a new input space where interaction designers can associate system actions to different fingers. However, relatively little is known about the performance of specific fingers as single touch points or when used together in a "chord." We present empirical results for accuracy, throughput, and subjective preference gathered in five experiments with 48 participants exploring all 10 fingers and 7 two-finger chords. Based on these results, we develop design guidelines for reasonable target sizes for specific fingers and two-finger chords, and a relative ranking of the suitability of fingers and two-finger chords for common multi-touch tasks. Our work contributes new knowledge regarding specific finger and chord performance and can inform the design of future interaction techniques and interfaces utilizing finger identification.
\end{abstract}

\section{Author Keywords}

touch input; finger identification; performance

\section{ACM Classification Keywords}

H.5.2 Information interfaces (e.g. HCI): User interfaces

\section{INTRODUCTION}

One way multi-touch devices switch between actions is by counting the number of simultaneous touch points. For example, with the iPad Pages word processor app you can move the text insertion point by a character with a one touch drag, by a word with a two touch drag, and by a paragraph with a three touch drag [1]. However, this multi-touch input space is limited because all touch points are treated equally - a onetouch drag performs the same action regardless whether the index finger, middle finger, or thumb is used.

To address this limitation, researchers have been developing techniques for multi-touch finger identification. This is where each touch point is labelled with the finger being used, and this extra finger information is used to trigger different actions. As an example, finger identification could enable the

Permission to make digital or hard copies of all or part of this work for personal or classroom use is granted without fee provided that copies are not made or distributed for profit or commercial advantage and that copies bear this notice and the full citation on the first page. Copyrights for components of this work owned by others than ACM must be honored. Abstracting with credit is permitted. To copy otherwise, or republish, to post on servers or to redistribute to lists, requires prior specific permission and/or a fee. Request permissions from permissions@ acm.org.

CHI'16, May 07-12, 2016, San Jose, CA, USA.

(C) 2016 ACM ISBN 978-1-4503-3362-7/16/05 ...\$15.00

DOI: http://dx.doi.org/10.1145/2858036.2858194
Pages app to overload a one touch drag with different actions: index finger to move the text insertion point by a character, middle finger for selecting one character, ring finger for flipping pages, and thumb for triggering common commands like undo. Researchers are already exploring approaches to finger identification sensing such as modelling geometric relationships of touch points $[2,13,36,53,24,50]$, overhead camera tracking [30, 52], special gloves [31], recognizing fingerprints [48, 22]; forearm electromyography [7], and artificial fingernails with RFID tags [49]. In anticipation of a robust, generalized technical solution to finger identification, researchers are already proposing interaction techniques utilizing finger identification (e.g. [7, 31, 48, 44, 16, 17, 24]).

Most research examining touch input performance has implicitly imposed the use of a single finger of the dominant hand $[21,34,11,46,8,5,40,39,45,42]$ or the dominant hand index finger and thumb for object transformation [54, 3]. Few studies focus on the accuracy and speed of specific fingers when used individually or when multiple fingers are used together as a chord [15]. The pointing accuracy and speed of the dominant index, thumb, and both thumbs have been studied in the context of hand-held devices [37, 41, 25, 4]. Thumb and finger chords have been indirectly evaluated in the context of interaction techniques [6, 18]. All five fingers of the dominant hand have been evaluated for directional strokes when used together in chords [24] and for pointing precision and speed when used individually [51, 12, 44].

To our knowledge, no previous study has examined the precision and speed for all fingers when used individually for target pointing and object dragging. In addition, no previous study has examined the precision and speed of specific two-finger chords for target pointing and object transformation with dragging, rotation, and scaling. We present empirical results for accuracy, throughput, and subjective preference gathered in 5 experiments spanning 2 studies with 48 participants exploring all 10 fingers and 7 two-finger chords. Based on these results, we develop design guidelines covering reasonable target sizes for specific fingers and two-finger chords, as well as a relative ranking of the suitability of fingers and two-finger chords for common multi-touch tasks. Our work contributes new knowledge regarding specific finger and chord performance and will inform future designers and researchers developing interaction techniques and interfaces utilizing finger identification. 


\section{RELATED WORK}

There are numerous studies evaluating aspects of touch interaction, including performance through Fitts' law experiments in pointing [47, 33, 14], dragging [10], and crossing tasks [26] as well as subjective preference [47, 14] and precision [43, 19]. The results have produced minimum recommended target sizes between $11.5 \mathrm{~mm}$ [51, 47] and $26 \mathrm{~mm}$ [19], and establish pointing throughput between 3 bps [33] and 8 bps [14]. However, none of these studies explicitly control which finger was used, although the dominant index finger is implied.

We focus our review on studies that imposed some control, or at least report which fingers are tested (see Table 1). We will use a concise notation to refer to fingers: $T_{d}, I_{d}, M_{d}$, $\mathrm{R}_{\mathrm{d}}, \mathrm{L}_{\mathrm{d}}$ for thumb, index, middle, ring, and little finger of the dominant hand and $T_{n}, I_{n}, M_{n}, R_{n}, L_{n}$ for the same fingers of the non-dominant hand (example in Figure 1a). The notation used for chords follows a similar pattern: for example $\mathrm{TI}_{d}$ refers to a thumb and index dominant hand chord.

\section{Specific tasks}

Pointing related. McManus et al. measured the inter-tap interval (the time between two consecutive finger taps) for all fingers [32]. They found the $I_{d}$ finger is fastest while the $R_{d}$ is slowest. In addition the dominant hand is faster than the non-dominant one. Lepinski et al. compared swipe gestures in different directions using three specific fingers and five 2to 5-finger chords [24]. They found chords with more fingers resulted in higher movement times and errors (but errors were often a result of failed tracking). Banovic et al. compared chord pointing to propose guidelines for designing multi-touch pie menus [6]. They compared dominant-hand 2-finger chords where either the $T_{d}$ or $I_{d}$ acts as an "anchor finger" on a central target and another finger selects a radial secondary target. The found chords anchored with $\mathrm{T}_{\mathrm{d}}$ were more error prone, and when anchored with $\mathrm{T}_{\mathrm{d}}, \mathrm{TL}_{\mathrm{d}}$ was significantly slower than all other fingers.

Transformations. Zhao et al., focused on the Rotate-ScaleTranslate (RST) transformation [54]. Even though the chord was not imposed per se, participants had to use either $\mathrm{TI}_{\mathrm{d}}$ or $\mathrm{TM}_{\mathrm{d}}$. Reporting time and throughput, they extended the Fitts' Index of Difficulty formula to the RST task. Hoggan et al. studied rotation gestures using the $\mathrm{TI}_{\mathrm{d}}$ [20]. They manipulated the angle, direction, diameter, and position of rotation. The results highlight ergonomic hand constrains: clockwise rotations are slower for initial angles less than $120^{\circ}$.

\section{Pointing}

Several studies have examined index finger or thumb pointing, with some controlling for multiple fingers.

Dominant index. Holtz et al. investigated "mental models" when people point at the centre of a cross [21]. They reported people typically offset touch position by $4 \mathrm{~mm}$ and were able to lower the offset to $1.6 \mathrm{~mm}$. Also studying touch offset, Möllers et al. found modelling approach angle during target acquisition could increase touch accuracy [34]. Based on a of typing on numeric keypads with various sizes and spacings, Herbert et al. recommend a key size of $20 \mathrm{~mm}$ [11].
MacKenzie et al. compared 1D and 2D pointing tasks on a smartphone while also varying the grasp [46]. They found $15 \%$ higher throughput for the 1D task and no effect of grasp. Bi et al. improved Fitts' law by introducing the FFitts model for small target acquisition on touchscreens [8]. By varying form factors (tablet, laptop, tabletop, public display, smartphone 2-handed, smartphone 1-handed), Bachynskyi et al. measured throughput and muscle activation [5]. They found an average throughput of $6.55 \mathrm{bps}$, with tabletop and 2-handed smartphone throughput about $20 \%$ higher and tablet and laptop about $11 \%$ lower. Sasangohar et al. measured mouse throughput on a tabletop to be $5.53 \mathrm{bps}$ compared to $3.83 \mathrm{bps}$ with touch input [45]. They also found a higher error rate for touch input. Po et al. found better performance for selecting targets in the lower visual field [42].

Dominant thumb. Park et al. studied one-handed touch accuracy on smartphone [40]. After analyzing the contact point pattern for different target sizes and locations, they proposed a solution to design keys yielding a higher success rate. Parhi et al. showed target sizes between 9 and $10 \mathrm{~mm}$ can be acquired using $\mathrm{T}_{\mathrm{d}}$ [39].

Dominant and non-dominant thumbs. Perry et al. compared $\mathrm{T}_{\mathrm{d}}$ and $\mathrm{T}_{\mathrm{n}}$ performance for tapping on a mobile phone when standing and walking [41]. They showed higher performance for $\mathrm{T}_{\mathrm{d}}$, on average $100 \mathrm{~ms}$ faster and $5 \%$ more accurate.

Dominant thumb and index. Ljubic et al. summarize existing Fitts' law models and showed that Fitts' law is a good predictor for pointing at rectangular targets on touchscreens [25]. They varied the form factor (tablet and smartphone) and the interaction (one-handed and two-handed).

Both thumbs, dominant-thumb and dominant-index. $\mathrm{Ng}$ et al. found that when people are encumbered while walking, smartphone interaction is significantly worse [37]. Azenkot et al. explored touch behaviour on soft QWERTY keyboards and studied users' precision [4]. With this data, they provided insight for the design of these keyboards.

Dominant fingers. Colley et al. measured pointing performance for the five fingers of the dominant hand [12]. They found significant differences for error and time between $I_{d}$ (best) and the $\mathrm{L}_{\mathrm{d}}$ (worst). The subjective rating of fingers confirmed their results: $I_{d}$ is perceived as more comfortable and faster, while $\mathrm{L}_{\mathrm{d}}$ is less comfortable and slower, than all other fingers. Roy et al. obtained similar results for dominant hand fingers: the reaction time, the execution time, the completion time, and the error rate were significantly better for $\mathrm{I}_{\mathrm{d}}$ compared to $\mathrm{L}_{\mathrm{d}}$ [44]. In both studies, no significant differences were found for other finger pairs. Wang et al. evaluated the tapping precision of all dominant hand fingers and found $I_{d}, M_{d}$, and $R_{d}$ are more precise than $T_{d}$ and $L_{d}$ [51]. They also reported that $\mathrm{L}_{\mathrm{d}}$ was perceived as harder to use.

Prior work imposing some control over fingers have primarily focused on pointing with few examining more than one or two fingers. With the exception of Zhao et al. and Hoggan et al., no prior work has examined precision and speed for all fingers in dragging or object transformation. 


\begin{tabular}{|c|c|c|c|}
\hline & SINGLE FINGERS & MULTIPLE FINGERS & ChORDS \\
\hline Pointing & $\begin{array}{l}\text { D-INDEX } \\
\text { Holtz } \text { et al. [21] (offset) } \\
\text { Möllers } \text { et al. [34] (offset) } \\
\text { Herbert } \text { et al. } \text { [11] (time, error) } \\
\text { MacKenzie } \text { et al. [46] (time, error, throughput) } \\
\text { Bi } \text { et al. [8] (time, error, accuracy) } \\
\text { Bachynskyi } \text { et al. [5] (throughput, muscle activation) } \\
\text { Sasangohar } \text { et al. [45] (time, error, throughput, preferences) } \\
\text { Po et al. [42] (time, error) } \\
\text { D-THUMB } \\
\text { Park et al. [40] (error, offset) } \\
\text { Parhi et al. }[39] \text { (time, error) }\end{array}$ & $\begin{array}{l}\text { THUMBS } \\
\text { Perry et al. [41] (time, error, IP) } \\
\text { D-THUMB, D-INDEX } \\
\text { Ljubic } \text { et al. [25] (time) } \\
\text { THUMBS, D-THUMB, D-INDEX } \\
\text { Ng } \text { et al. [37] (time, error, accuracy) } \\
\text { Azenkot } \text { et al. [4] (speed, accuracy, offset) } \\
\text { D-FINGERS } \\
\text { Wang et al. [51] (accuracy, offset) } \\
\text { Colley et al. [12] (time, error, preferences) } \\
\text { Roy et al. [44] (time, error, throughput) }\end{array}$ & $\begin{array}{l}\text { 2-FINGER CHORDS } \\
\text { Banovic } \text { et al. [6] (time, error) }\end{array}$ \\
\hline Dragging & None & None & None \\
\hline Transformations & None & None & $\begin{array}{l}\text { D-THUMB+INDEX OR D-THUMB+MIDDLE } \\
\text { Zhao } \text { et al. [54] (time, RST ID model) } \\
\text { Hoggan } \text { et al. }[20] \text { (time) }\end{array}$ \\
\hline
\end{tabular}

Table 1: Summary of criteria evaluated in prior work for single, multiple fingers and chords in pointing, dragging and transformations tasks.

\section{STUDY 1: TARGET SELECTION}

The goal of the first study is to determine optimal target sizes for selection using different fingers and different two-finger chords. We use a range of circular target sizes rather than the single cross hair used by Bi et al.'s FFitts law study [8]. In a pilot study, we found participants tightly pinched their fingers together when prompted with a cross hair, but as a circular target becomes larger it encourages more "comfortable" target selection with two-finger chords. These results are also used to select target sizes for our second study.

\section{Participants}

We recruited 12 volunteers: mean age 23.1 (SD 3.5), 5 male, 1 left-handed, all touchscreen users. Remuneration was $\$ 10$.

\section{Apparatus}

The experiment ran on a Nexus 10 tablet and was written in C++ QT 5.3. Visual stimulus and feedback were kept simple to limit additional latency. $\mathrm{Ng}$. et al.'s method [38] with a $240 \mathrm{fps}$ camera revealed an end-to-end latency of $100 \mathrm{~ms}$, making our apparatus an ecologically valid testbed on par with today's mobile and tablet apps. Note that while lower latencies can increase absolute performance, we are interested in a relative performance comparison between fingers. The $264 \times 178 \mathrm{~mm}$ display has a resolution of $2560 \times 1600 \mathrm{px}$, a density of $11.8 \mathrm{px} / \mathrm{mm}$ (300 PPI). Participants were seated at a desk as they used the tablet laid flat in landscape orientation. Placing the tablet flat avoids confounding effects from grip type and fatigue and is consistent with previous touch studies $[6,26]$. Our results are limited to desktop use, but in practice, forearm-to-tablet angles appear similar when set on a lap or held by one hand.

\section{Task}

The task required participants to tap on a circular target using a specific finger or two-finger chord (Figure 1). Targets were displayed one at a time at random positions within the display. If the touch points were outside the circle, no error feedback was displayed. No specific instructions were given to the participant regarding speed or accuracy since the objective is to measure a comfortable target size. (a)

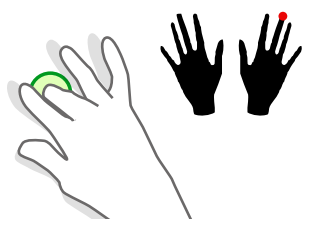

(b)

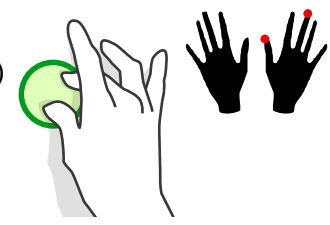

Figure 1: Study 1 task examples. Participants tapped on circular targets (shown in green here) using specific fingers or chords: (a) example using finger $M_{d}$; (b) example using chord $T M_{d}$. The finger or chord to use was indicated with hand icons (shown in black here).

\section{Protocol}

After answering a short demographic questionnaire, the experiment task was explained along with the additional requirement of using a specific finger or two-finger chord. The participant then began the experiment. The experiment design groups trials for each finger or chord together, and divides the experiment into finger and chord sections. Participants could practice for an unlimited time at the beginning of each section. A graphic hand icon (black hands in Figure 1) indicated when a new finger or chord was to be used for the next group of trials. This message was shown for at least 5 seconds before a continue button appeared to make participants aware of the change and encourage breaks. On average, the experiment was 40 minutes long.

\section{Design}

The primary independent variable is the finger or chord used to CONTACT the touch display. We tested 17 different CONTACTS covering all 10 FINGERS across both hands $\left(T_{d}, I_{d}\right.$, $M_{d}, R_{d}, L_{d}$ for the dominant hand and $T_{n}, I_{n}, M_{n}, R_{n}, L_{n}$ for the non-dominant hand, see example in Figure 1a) and 7 types of two finger CHORDS (dominant hand "pinch" chords $\mathrm{TI}_{\mathrm{d}}, \mathrm{TM}_{\mathrm{d}}, \mathrm{TR}_{\mathrm{d}}, \mathrm{TL}_{\mathrm{d}}$ and dominant hand "non-pinch" chords $\mathrm{IM}_{\mathrm{d}}, \mathrm{MR}_{\mathrm{d}}, \mathrm{RL}_{\mathrm{d}}$, see example in Figure 1b). Using "dominant" or "non-dominant" normalizes left- and right-handed participants. Some of these chords like $\mathrm{TI}_{d}, \mathrm{TM}_{\mathrm{d}}, \mathrm{IM}_{\mathrm{d}}$ and $\mathrm{MR}_{\mathrm{d}}$ are already used on multi-touch devices to zoom, rotate and scroll. We added other similar chords within the bounds of a reasonable experiment duration. 
A second independent variable is the selection TOLERANCE, which in this experiment is the circular target diameter. Six TOLERANCES were investigated. For FINGER CONTACTS: $17.5,15,12.5,10,7.5,5 \mathrm{~mm}$. For two-finger CHORD CONTACTS: 40, 36, 32, 28, 24, $20 \mathrm{~mm}$. A pilot experiment indicated these sizes spanned target selections from difficult and uncomfortable to moderate and more than comfortable.

The experiment has 3 BLOCKS, with each block containing 6 repetitions of all combinations of factors. All trials for one setting of CONTACT are grouped together meaning participants use the same finger or chord for a series trials covering the range of TOLERANCES. This reduces the cognitive load during the experiment and keeps the focus on accuracy, not how quickly people can change between different fingers or chords. The order of CONTACTS was randomized with the following constraints: all CHORDS and all FINGERS were grouped into two sections, and section order was counterbalanced across participants: in the finger section, FINGERS were selected such that they alternated between hands; and in the chord section, CHORDS were randomly selected such that they alternated between "pinch" and "non-pinch". In summary, there were: 17 CONTACTS $\times 3$ BLOCKS $\times 6$ TOLERANCES $\times 6$ REPETITIONS $=1,836$ TRIALS per participant.

\section{Analysis}

All analyses are multi-way ANOVA: participant is a random variable using the REML procedure of the SAS JMP package. Tukey tests are used post-hoc when significant effects are found.

\section{Results}

This section reports statistical tests with FINGERS and CHORDS analysed separately. Statistical results are presented briefly and concisely, the reader is encourage to examine Figure 2 for the overall trend of error rates and consult Table 2 for recommended sizes based on this analysis.

\section{Fingers}

Learning and/or Fatigue - No significant effect for BLOCK on Error, all blocks included in analysis.

Error - Significant effect of FINGER on Error $\left(F_{9,99}=4.5\right.$, $p<.0001)$. Post hoc tests show : $\mathrm{R}_{\mathrm{n}}(28 \%)$ has a significantly higher error rate $(p<.05)$ compared to $\mathrm{M}_{\mathrm{d}}(17 \%), \mathrm{I}_{\mathrm{n}}(17 \%)$ and $I_{d}(14 \%)$; and $I_{d}$ has also a significant lower error rate $(p<.05)$ compared to $\mathrm{R}_{\mathrm{n}}, \mathrm{L}_{\mathrm{d}}, \mathrm{L}_{\mathrm{n}}, \mathrm{T}_{\mathrm{n}}$ and $\mathrm{T}_{\mathrm{d}}$ (means between $24 \%$ and $28 \%$ ). Significant main effect of TOLERANCE on

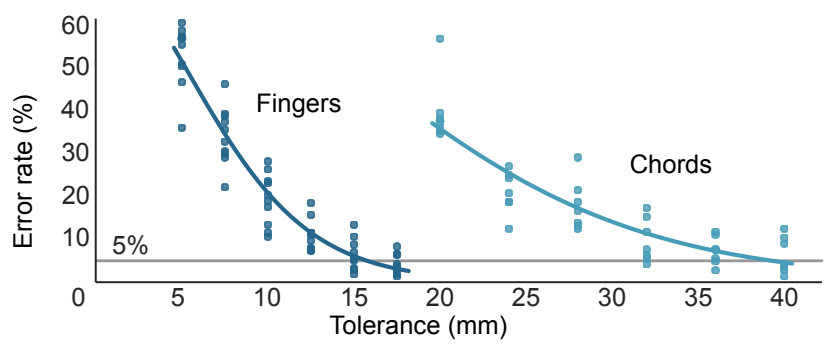

Figure 2: Error rate by TOLERANCE for CONTACT.
Error for each FINGER (all $p<.0001$ ) follow the expected pattern. Post hoc tests show 5 and $7.5 \mathrm{~mm}$ tolerances have higher error rates $(p<.05)$. Treating each TOLERANCE separately, there is a significant main effect of FINGER on Error. FINGER error rates differ for all with some significant differences, except the $12.5 \mathrm{~mm}$ tolerance showing no significant difference (combined mean 7\%).

\section{Chords}

Learning and/or Fatigue - Significant effect for BLOCK on Error $\left(F_{2,22}=6.3, p<.007\right)$. Post hoc test show block 3 has a higher error rate compared to 1 and $2(p<.05)$ suggesting a fatigue effect. Blocks 3 is removed from subsequent analysis.

Error - No significant main effect of CHORD on Error (means ranging from $12 \%$ to $25 \%$ ) but significant main effect of TOLERANCE on Error for each FINGER (all $p<.0001$ ). Post hoc tests reveal that the $20 \mathrm{~mm}$ tolerance has significantly higher errors $(p<.05)$ than all other tolerances.

Contact Characteristics - To examine comfort, we compute the mean distance (in $\mathrm{mm}$ ) between the two fingers at the moment of selection as an indicator of how relaxed participants were when fitting their fingers into the target. When the mean distance is plotted against target size (Figure 3), we consider that a plateau in distance indicates the corresponding target sizes are more comfortable to select.

TOLERANCE had a significant effect on that distance $\left(F_{6,451}=7.8, p<.0001\right)$. Post-hoc tests show that the distance between fingers for target widths of 40 and $36 \mathrm{~mm}$ (mean 16.8 $\mathrm{mm}$ ) are significantly larger than for 24 and $20 \mathrm{~mm}$ (mean $14.4 \mathrm{~mm})(p<.01)$. An analysis of each CHORD separately confirms this result for $\mathrm{IM}_{\mathrm{d}}, \mathrm{RL}_{\mathrm{d}}, \mathrm{TM}_{\mathrm{d}}$ and $\mathrm{TR}_{\mathrm{d}}$ (all $p<.05$ ). With $\mathrm{MR}_{\mathrm{d}}$ targets, only $40 \mathrm{~mm}$ and $20 \mathrm{~mm}$ were significantly different $(p<.05)$; with $\mathrm{TL}_{\mathrm{d}}$, the distance was significantly larger with targets of $40 \mathrm{~mm}$ than of 20 and $24 \mathrm{~mm}(p<.01)$ Finally, despite a significant effect, a post-hoc test showed no difference between TOLERANCE for $\mathrm{TI}_{\mathrm{d}}$.

\section{Discussion}

For most fingers, except $\mathrm{L}_{\mathrm{n}}, \mathrm{R}_{\mathrm{n}}$ and $\mathrm{L}_{\mathrm{d}}$, a target size above $17.5 \mathrm{~mm}$ comfortably allows an error rate below 5\%. This result is in the range of target sizes recommended by previous studies (11.5 mm [51, 47] and $26 \mathrm{~mm}$ [19]). For chords, the minimum size for two fingers needs to be at least $36 \mathrm{~mm}$ and often $40 \mathrm{~mm}$. Recall that in our study, participants were not instructed to be accurate nor were they provided immediate error feedback. To assess accuracy, we intentionally test

\begin{tabular}{|c|c|c|c|c|c|c|c|c|c|c|}
\hline & $\mathrm{L}_{\mathrm{n}}$ & $\mathrm{R}_{\mathrm{n}}$ & $M_{n}$ & $\mathrm{I}_{\mathrm{n}}$ & $T_{n}$ & $\mathrm{~T}_{\mathrm{d}}$ & $\mathrm{I}_{\mathrm{d}}$ & $M_{d}$ & $\mathrm{R}_{\mathrm{d}}$ & $\mathrm{L}_{\mathrm{d}}$ \\
\hline Tol (mm) & 17.5 & 17.5 & 17.5 & 17.5 & 17.5 & 17.5 & 17.5 & 15 & 17.5 & 17.5 \\
\hline \multirow[t]{2}{*}{ Err \% } & $6.5 \%$ & $6.5 \%$ & $1.4 \%$ & $1.9 \%$ & $3.2 \%$ & $3.2 \%$ & $1.9 \%$ & $1.9 \%$ & $4.2 \%$ & $8.3 \%$ \\
\hline & $\mathrm{TI}_{\mathrm{d}}$ & $\mathrm{TM}_{\mathrm{d}}$ & $\mathrm{TR}_{\mathrm{d}}$ & $\mathrm{TL}_{\mathrm{d}}$ & $\mathrm{IM}_{\mathrm{d}}$ & $\mathrm{MR}_{\mathrm{d}}$ & $\mathrm{RL}_{\mathrm{d}}$ & & & \\
\hline $\begin{array}{r}\text { Tol (mm) } \\
\text { Err \% }\end{array}$ & $\begin{array}{c}36 \\
1.4 \%\end{array}$ & $\begin{array}{c}40 \\
4.2 \%\end{array}$ & $\begin{array}{c}40 \\
9.0 \%\end{array}$ & $\begin{array}{c}40 \\
12.5 \%\end{array}$ & $\begin{array}{c}36 \\
2.8 \%\end{array}$ & $\begin{array}{c}40 \\
3.5 \%\end{array}$ & $\begin{array}{c}40 \\
10.4 \%\end{array}$ & & & \\
\hline
\end{tabular}

Table 2: TOLERANCE at which the error rate of a CONTACT starts being under 5\%. The bold values correspond to the CONTACT that never reached the $5 \%$ (reported values are the error rate for the maximal TOLERANCE). 


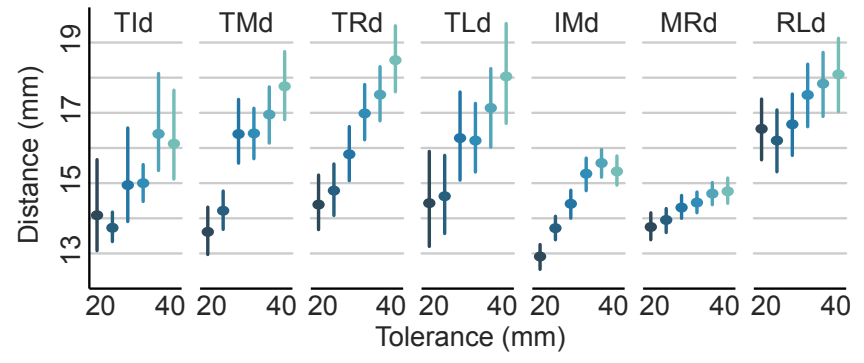

Figure 3: Mean distance between the two fingers of given CHORD for each TOLERANCE.

pointing with some TOLERANCE values smaller than the recommended sizes in the following study.

\section{STUDY 2: PERFORMANCE AND PREFERENCE}

The goal of the second study is to measure the performance of different fingers and chords with four common tasks: pointing, dragging, scaling, and rotating. The study design uses four similar "Fitts-like" experiments, with each experiment dedicated to a single task. All experiments were run simultaneously as one study, with participants recruited and randomly assigned to each. Performance is measured using task time, error rate, throughput, and Fitts' Law regression model parameters. Preference is measured using a subjective rating.

In this section we describe aspects common to all four experiments. The specific tasks, design, and results are provided for each experiment in later sections.

\section{Apparatus}

All experiments use the same apparatus as Study 1.

\section{Participants}

A total of 36 participants were recruited. All used multi-touch devices. Participants were assigned to experiments as follows: 12 completed the pointing experiment; 12 completed the dragging experiment; and the remaining 12 completed both scaling and rotating experiments. Demographics are provided in each experiment section. Remuneration was \$10.

\section{Protocol}

The procedure for all experiments are similar to Study 1, but with different tasks and additional feedback for errors and error rate. When demonstrating the task, the experimenter explained what actions were deemed successful and which caused errors and instructed participants to perform the task as fast as possible while keeping an error rate near $4 \%$. To assist with this target, the software displayed the error rate for the current CONTACT group. When all experiment trials were completed, participants rated their perceived easeof-use, speed, accuracy, and (lack of) fatigue for every tested finger and chord. A continuous, numeric scale was used from 1 (lowest) to 5 (highest) with fractional ratings permitted (e.g. 3.5). Each experiment averaged between 30 and 60 minutes.

\section{Design}

The primary independent variables are the same or similar across the four experiments.
Like Study 1, the primary independent variable is CONTACT All 17 CONTACTS spanning 10 FINGERS and 7 CHORDS are evaluated in the pointing and dragging experiments. Only CHORDS apply to scaling and rotation tasks. While all 7 CHORDS were evaluated in the rotation experiment only the 4 opposable "pinch" CHORDS were evaluated for scaling given the required movement.

The task difficulty is captured by two independent variables, TOLERANCE and AMPLITUDE. The specific meanings and levels are explained in the four experiment sections.

All experiments have 3 BLOCKS, with each block containing 6 repetitions for all combinations of factors. Like Study 1, all trials for one setting of CONTACT were grouped together (i.e. the same finger or chord is used for a series of trials covering all combinations of TOLERANCE and AMPLITUDE) and CONTACTS are delivered in contiguous sections, with each section ordering contacts in partially-constrained randomized orders (e.g. alternating hands for FINGERS). For each CONTACT, all trials for each TOLERANCE were grouped together with randomized AMPLITUDE order, and TOLERANCE order was counter-balanced across BLOCKS.

\section{Fitts' Law Modelling}

In each experiment, we model the performance of each CONTACT with Fitts' law [28] using the Shannon formulation for Index of Difficulty (ID) [27, 29]:

$$
\text { Time }=a+b \log _{2}\left(\frac{\text { AMPLITUDE }}{\text { TOLERANCE }}+1\right)
$$

All experiments have 3 TOLERANCE levels and 2 AMPLITUDE levels chosen such that when combined, they create a reasonable range of ID levels. We report Index of Performance $\left(I P=\frac{1}{b}\right)$ for completeness, but use Throughput $(T P)$ as the primary measure to summarize overall performance of each CONTACT. The effective width $W_{e}$ formulation is used as recommended by ISO 9241 [23]:

$$
T P=I D_{e} / \overline{\text { Time }}=\log _{2}\left(\frac{\text { AMPLITUDE }}{W e}+1\right) / \overline{\text { Time }}
$$

\section{Data Logging Error}

A technical error in the logging system caused 1 out of 6 trials $(16 \%)$ to be overwritten. Fortunately, the pattern of loss is related directly to how an index for logging each trial to a database was calculated using modulo arithmetic. Since it was a modulo error, the pattern is counter-balanced across conditions. There were no partially corrupted trials, so no noise was introduced. In all analysis, we aggregate multiple repetitions of trials, further reducing any impact of the error.

\section{Analysis}

All analyses are multi-way ANOVA: participant is a random variable using the REML procedure of the SAS JMP package. Tukey tests are used post-hoc when significant effects are found. Since task durations are typically not normally distributed, median times are used when aggregating. 


\section{STUDY 2, EXPERIMENT 1: TARGET POINTING}

The goal of this experiment is to measure the performance of different fingers and chords when pointing at targets. 12 participants were assigned to this experiment ( 7 females, mean age 22.2, SD 2.2). Refer to the Study 2 description for common apparatus, protocol, design, and analysis.

\section{Task}

The task required participants to point at targets as fast as possible using a specific finger or chord while maintaining an error rate around $4 \%$. Each trial began when the participant touched down on a circular starting area with diameter $2 \mathrm{~cm}$ for fingers and $4 \mathrm{~cm}$ for chords. The trial ended when the participant touched and released another circular target placed a controlled distance away (Figure 4). If any of the touches were outside the bounds of either target, the trial was marked as an error and the display flashed orange. (a)

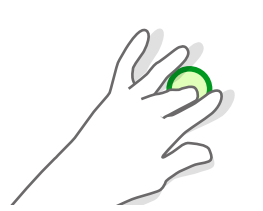

(b)

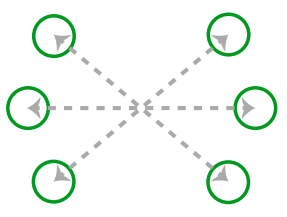

Figure 4: Pointing task. Participants tapped on circular targets (shown in green here) using specific fingers or chords: (a) example using finger $M_{n}$;(b) target direction variations.

\section{Design}

In this task, TOLERANCE corresponds to the target diameter and AMPLITUDE corresponds to the distance between the centre of the starting area to the centre of the target. Different TOLERANCES and AMPLITUDES were used for FINGERS and CHORDS. For FINGERS, the TOLERANCES were 1, 1.5, and $2 \mathrm{~cm}$, and the AMPLITUDES were 4 and $19 \mathrm{~cm}$. The six combinations of TOLERANCE and AMPLITUDE generate IDs between 1.6 and 4.3 bits. For CHORDS, the TOLERANCES were $3,3.5$, and $4 \mathrm{~cm}$, and the AMPLITUDES were 5 and $17 \mathrm{~cm}$. The six combinations of TOLERANCE and AMPLITUDE generate IDs between 1.2 and 2.7 bits. Note that our ID range is constrained by reasonable target sizes and achievable distances on the tablet.

The 6 REPETITIONS varied target direction from left-to-right, top-left to bottom-right, bottom-left to top-right, and symmetric right-to-left directions. Using all directions as per ISO 9241 [23] would have severely reduced the maximum AMPLITUDES and range of IDs. In summary, the design was: 17 CONTACTS $\times 3$ BLOCKS $\times 3$ TOLERANCES $\times 2$ AMPLITUDES $\times 6$ REPETITIONS.

\section{Results}

This section reports statistical tests and Fitts' Law modelling with FINGERS and CHORDS analysed separately. Key values are summarized in Tables 3 and 4, and trends for Throughput and Preference are summarized in Figure 8a-b in the Discussion section where all experiments may be visually compared.

\begin{tabular}{rcccccccccc} 
& $\mathrm{L}_{\mathrm{n}}$ & $\mathrm{R}_{\mathrm{n}}$ & $\mathrm{M}_{\mathrm{n}}$ & $\mathrm{I}_{\mathrm{n}}$ & $\mathrm{T}_{\mathrm{n}}$ & $\mathrm{T}_{\mathrm{d}}$ & $\mathrm{I}_{\mathrm{d}}$ & $\mathrm{M}_{\mathrm{d}}$ & $\mathrm{R}_{\mathrm{d}}$ & $\mathrm{L}_{\mathrm{d}}$ \\
\cline { 2 - 11 } $\mathrm{a}$ & 0.22 & 0.22 & 0.23 & 0.19 & 0.30 & 0.18 & 0.14 & 0.20 & 0.22 & 0.27 \\
$\mathrm{~b}$ & 0.16 & 0.15 & 0.13 & 0.15 & 0.14 & 0.14 & 0.13 & 0.12 & 0.13 & 0.13 \\
$r^{2}$ & 0.99 & 0.99 & 1.00 & 1.00 & 1.00 & 1.00 & 0.99 & 0.99 & 1.00 & 1.00 \\
\cline { 2 - 11 } Time & 0.69 & 0.67 & 0.61 & 0.61 & 0.70 & 0.59 & 0.52 & 0.54 & 0.59 & 0.64 \\
\cline { 2 - 11 }$T P$ & 4.28 & 4.43 & 4.86 & 4.91 & 4.25 & 5.16 & 5.85 & 5.57 & 5.13 & 4.65 \\
$I P$ & 6.13 & 6.47 & 7.55 & 6.87 & 7.13 & 7.09 & 7.63 & 8.65 & 7.87 & 7.72
\end{tabular}

Table 3: Summary of FINGER values for pointing experiment. Best and worst values are highlighted in green and gray respectively.

\section{Fingers}

Learning Effect - No significant effects found for BLOCK on Time or Error, all blocks included in analysis.

Error - Significant effect of FINGER on Error $\left(F_{9,649}=2.1\right.$, $p<.05)$. Post hoc tests found no pairwise differences. Mean error rates all between $2.07 \%$ and $4.08 \%$. As expected, effects of TOLERANCE or AMPLITUDE on Error were significant.

Time - Significant effect of FINGER on Time $\left(F_{9,649}=33.5\right.$, $p<.0001)$. Post hoc tests show: $\mathrm{M}_{\mathrm{d}}$ and $\mathrm{I}_{\mathrm{d}}$ faster than all others (all $p<.0001) ; \mathrm{T}_{\mathrm{n}}$ slower than all but $\mathrm{R}_{\mathrm{n}}$ and $\mathrm{L}_{\mathrm{n}}($ all $p<.0002)$; $\mathrm{L}_{\mathrm{d}}$ slower than all other dominant fingers $(p<.0001)$ As expected, effects of TOLERANCE or AMPLITUDE on Time were significant.

Fitts' Law Modelling - All FINGER models have $r^{2}>.98$, see Table 3 for model parameters.

Throughput - Significant effect for FINGER on TP $\left(F_{9,649}=32.4, p<.0001\right)$. Post hoc tests show: all dominant fingers have higher TP than $\mathrm{L}_{\mathrm{n}}$ and $\mathrm{T}_{\mathrm{n}}(p<.01) ; \mathrm{I}_{\mathrm{d}}, \mathrm{M}_{\mathrm{d}}, \mathrm{T}_{\mathrm{d}}$ and $\mathrm{R}_{\mathrm{d}}$ have higher TP than $\mathrm{R}_{\mathrm{n}}, \mathrm{L}_{\mathrm{n}}$ and $\mathrm{T}_{\mathrm{n}}(p<.01) ; \mathrm{I}_{\mathrm{d}}, \mathrm{M}_{\mathrm{d}}$ and $\mathrm{T}_{\mathrm{d}}$ have higher $T P$ than $\mathrm{L}_{\mathrm{n}}$ and all non-dominant fingers except $\mathrm{I}_{\mathrm{n}}(p<.05) ; \mathrm{I}_{\mathrm{d}}$ and $\mathrm{M}_{\mathrm{d}}$ have higher TP than all fingers but $\mathrm{T}_{\mathrm{d}}$ $(p<.01)$.

Ratings - Significant effects for FINGER on Ease-of-use, Speed, Accuracy, and Fatigue $\left(F_{9.99}>4.9, p<.0001\right)$. Post hoc tests show a consistent trend (all $p<.0001$ ): $\mathrm{I}_{\mathrm{d}}, \mathrm{M}_{\mathrm{d}}, \mathrm{I}_{\mathrm{n}}$ and $T_{d}$ are rated higher than $L_{n}$ and $R_{n}$ (Ease-of-use, Speed), $R_{n}$ (Accuracy) and $\mathrm{L}_{\mathrm{n}}, \mathrm{R}_{\mathrm{d}}$ (Fatigue).

\section{Chords}

Learning Effect - A significant effect for BLOCK on Time $\left(F_{2,22}=5.4, p<.05\right)$ but not Error. Block 1 is significantly slower than Blocks 2 and 3, Block 1 is removed from subsequent analysis.

Error - Significant effect of CHORD on Error $\left(F_{6,451}=2.4\right.$, $p<.05)$. Post hoc tests show $\mathrm{TL}_{\mathrm{d}}$ causes more errors than $\mathrm{MR}_{\mathrm{d}}$ (all rates between $1.2 \%$ and $4.0 \%$ ). As expected TOLERANCE or AMPLITUDE have a significant effect on Error.

Time - Significant effect for CHORD on Time $\left(F_{6,451}=6.7\right.$, $p<.0001)$. Post hoc tests show: $\mathrm{TI}_{\mathrm{d}}, \mathrm{IM}_{\mathrm{d}}$, and $\mathrm{TM}_{\mathrm{d}}$ significantly faster than $\mathrm{TR}_{\mathrm{d}}($ all $p<.02) ; \mathrm{IM}_{\mathrm{d}}$ and $\mathrm{TM}_{\mathrm{d}}$ faster than $\mathrm{TR}_{\mathrm{d}}$ and $\mathrm{TL}_{\mathrm{d}}($ all $p<.01)$ As expected, effects of TOLERANCE or AMPLITUDE on Time were significant.

Fitts' Law Modelling - All CHORD models have $r^{2} \geq .97$, see Table 4 for model parameters. 


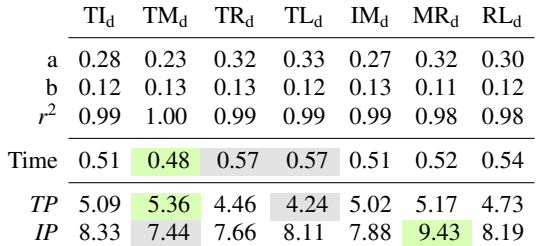

Table 4: Summary of $C H O R D$ values for pointing experiment. Best and worst values are highlighted in green and gray respectively.

Throughput - Significant effect for CHORD on TP $\left(F_{6,451}=6.5, p<.0001\right)$. Post hoc tests show: $\mathrm{TM}_{\mathrm{d}}$ has higher $T P$ than $\mathrm{RL}_{\mathrm{d}}, \mathrm{TR}_{\mathrm{d}}$ and $\mathrm{TL}_{\mathrm{d}}(p<.05) ; \mathrm{TM}_{\mathrm{d}}, \mathrm{TI}_{\mathrm{d}}$ and $\mathrm{MR}_{\mathrm{d}}$ have higher $T P$ than $\mathrm{TL}_{\mathrm{d}}(p<.05)$.

Ratings - Significant effects for CHORD on Ease-of-use, Speed, Accuracy, and Fatigue $\left(F_{9,99}>4.6, p<.001\right)$. Post hoc tests show a near consistent trend (all $p<.001$ ): $\mathrm{IM}_{\mathrm{d}}, \mathrm{MR}_{\mathrm{d}}$, $\mathrm{TI}_{\mathrm{d}}$ and $\mathrm{TM}_{\mathrm{d}}$ are rated higher than $\mathrm{RL}_{\mathrm{d}}$ and $\mathrm{TR}_{\mathrm{d}}$ (Ease-ofuse), $\mathrm{TL}_{\mathrm{d}}$ (Speed) and $\mathrm{RL}_{\mathrm{d}}$ and $\mathrm{TR}_{\mathrm{d}}$ (Fatigue); $\mathrm{IM}_{\mathrm{d}}$ and $\mathrm{TI}_{\mathrm{d}}$ are rated higher than $\mathrm{TL}_{\mathrm{d}}$ for Accuracy.

\section{STUDY 2, EXPERIMENT 2: OBJECT DRAGGING}

The goal of this experiment is to measure performance and preference for different fingers and chords when dragging an object. 12 participants were assigned to this experiment (6 female, mean age 23.8, SD 3.5). Refer to the Study 2 description for common apparatus, protocol, design, and analysis.

\section{Task}

The task required participants to drag a token into a target area as fast as possible using a specific finger or chord while maintaining a 4\% error rate. Each trial began when the participant touched down on a circular token with diameter $1.75 \mathrm{~cm}$ for fingers and $3 \mathrm{~cm}$ for chords. Without lifting their finger(s), they dragged the token into a circular target area placed a controlled distance away (Figure 5). The trial ended when the token was released inside the target area. If any part of the token was outside the target area when released, the trial was marked as an error and the display flashed orange.

\section{Design}

In this task, TOLERANCE corresponds to the difference between the target area diameter and the diameter of the token (Figure 5b). AMPLITUDE corresponds to the distance between the centre of the token starting position to the centre of the target area. Different TOLERANCES and AMPLITUDES were used for FINGERS and CHORDS. For FINGERS, the TOLERANCES were $0.5,1$, and $1.5 \mathrm{~cm}$, and the AMPLITUDES were 3 and $17 \mathrm{~cm}$. The six combinations of TOLERANCE and AMPLITUDE generate IDs between 1.6 and 5.1 bits. For CHORDS, the TOLERANCES were also 0.5 , 1 , and $1.5 \mathrm{~cm}$, but the AMPLITUDES were 4 and $15.5 \mathrm{~cm}$. The six combinations of TOLERANCE and AMPLITUDE generate IDs between 1.9 and 5.0 bits. The 6 REPETITIONS varied the target direction in the same way as the pointing experiment. In SUmmary: 17 CONTACTS $\times 3$ BLOCKS $\times 3$ TOLERANCES $\times$ 2 AMPLITUDES $\times 6$ REPETITIONS.
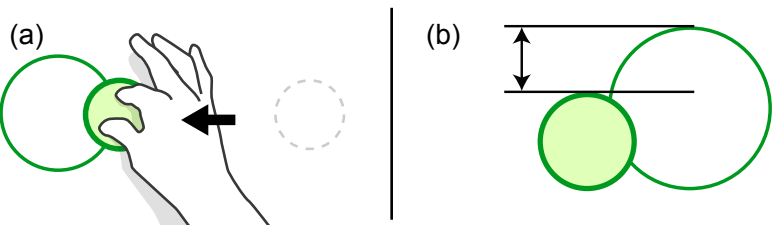

Figure 5: Dragging task. Participants dragged a circular token (shown in green here) to a target area using specific fingers or chords: (a) example using finger $\mathbf{T I}_{\mathbf{d}}$; (b) task TOLERANCE.

\begin{tabular}{rcccccccccc} 
& $\mathrm{L}_{\mathrm{n}}$ & $\mathrm{R}_{\mathrm{n}}$ & $\mathrm{M}_{\mathrm{n}}$ & $\mathrm{I}_{\mathrm{n}}$ & $\mathrm{T}_{\mathrm{n}}$ & $\mathrm{T}_{\mathrm{d}}$ & $\mathrm{I}_{\mathrm{d}}$ & $\mathrm{M}_{\mathrm{d}}$ & $\mathrm{R}_{\mathrm{d}}$ & $\mathrm{L}_{\mathrm{d}}$ \\
\cline { 2 - 10 } $\mathrm{a}$ & 0.46 & 0.45 & 0.43 & 0.55 & 0.51 & 0.40 & 0.39 & 0.39 & 0.41 & 0.38 \\
$\mathrm{~b}$ & 0.35 & 0.32 & 0.30 & 0.28 & 0.34 & 0.32 & 0.25 & 0.27 & 0.27 & 0.31 \\
$r^{2}$ & 0.86 & 0.85 & 0.85 & 0.80 & 0.80 & 0.87 & 0.84 & 0.81 & 0.83 & 0.86 \\
\cline { 2 - 10 } Time & 1.14 & 1.08 & 1.01 & 1.11 & 1.17 & 1.03 & 0.88 & 0.93 & 0.94 & 1.00 \\
\cline { 2 - 10 }$T P$ & 1.58 & 1.57 & 2.08 & 1.64 & 1.72 & 1.87 & 1.97 & 2.04 & 2.12 & 2.33 \\
$I P$ & 2.89 & 3.15 & 3.35 & 3.53 & 2.96 & 3.14 & 3.96 & 3.69 & 3.72 & 3.18
\end{tabular}

Table 5: Summary of FINGER values for dragging experiment. Best and worst values are highlighted in green and gray respectively.

\section{Results}

As before, this section reports statistical tests and Fitts' Law modelling with FINGERS and CHORDS analysed separately. Key values are summarized in Tables 5 and 6, and trends for Throughput and Preference are summarized in Figure 8d-e in the Discussion section.

\section{Fingers}

Learning Effect - No significant effects found for BLOCK on Time or Error, all blocks included in analysis.

Error - No significant effect of FINGER on Error (error rates all between $1.77 \%$ and $3.56 \%$ ). As expected, effects of TOLERANCE or AMPLITUDE on Error were significant.

Time - Significant effect of FINGER on Time $\left(F_{9,649}=29.5\right.$, $p<.0001)$. Post hoc tests show: $\mathrm{I}_{\mathrm{d}}$ and $\mathrm{M}_{\mathrm{d}}$ are faster than $\mathrm{L}_{\mathrm{d}}$ and all non-dominant fingers (all $p<.0001) ; \mathrm{T}_{\mathrm{n}}$ slower than all but $\mathrm{L}_{\mathrm{n}}($ all $p<.01)$; and $\mathrm{T}_{\mathrm{n}}, \mathrm{L}_{\mathrm{n}}, \mathrm{R}_{\mathrm{n}}$ are slower than all dominant fingers (all $p<.0001$ ); As expected, effects of TOLERANCE or AMPLITUDE on Time were significant.

Fitts' Law Modelling - All FINGER models have $r^{2}$ between .67 and .75 , see Table 3 for model values.

Throughput - Significant effect for FINGER on TP $\left(F_{9,649}=7.5, p<.0001\right)$. Post hoc tests show: $\mathbf{M}_{\mathrm{n}}$ and all dominant fingers but $\mathrm{T}_{\mathrm{d}}$ have higher TP than $\mathrm{T}_{\mathrm{n}}(p<.05) ; \mathrm{I}_{\mathrm{d}}, \mathrm{M}_{\mathrm{d}}$ and $\mathrm{R}_{\mathrm{d}}$ have higher $T P$ than $\mathrm{R}_{\mathrm{n}}, \mathrm{L}_{\mathrm{n}}$ and $\mathrm{T}_{\mathrm{n}}(p<.05)$.

Ratings - Significant effects for FINGER on Ease-of-use, Speed, Accuracy, and Fatigue $\left(F_{9,99}>4.0, p<.001\right)$. Post hoc tests show a consistent general trend (all $p<.001$ ): $\mathrm{I}_{\mathrm{d}}, \mathrm{M}_{\mathrm{d}}$ and $I_{n}$ are rated higher than $L_{d}, R_{n}$ and $L_{n}$ (Ease-of-use and Speed) and $R_{n}$ and $L_{d}$ (Fatigue). $I_{d}$ and $M_{d}$ are also rated higher than $R_{n}$ and $L_{n}$ for Accuracy.

\section{Chords}

Learning Effect - No significant effects found for BLOCK on Time or Error, all blocks included in analysis. 


\begin{tabular}{rccccccc} 
& $\mathrm{TI}_{\mathrm{d}}$ & $\mathrm{TM}_{\mathrm{d}}$ & $\mathrm{TR}_{\mathrm{d}}$ & $\mathrm{TL}_{\mathrm{d}}$ & $\mathrm{IM}_{\mathrm{d}}$ & $\mathrm{MR}_{\mathrm{d}}$ & $\mathrm{RL}_{\mathrm{d}}$ \\
\cline { 2 - 8 } $\mathrm{a}$ & 0.55 & 0.59 & 0.48 & 0.46 & 0.39 & 0.50 & 0.60 \\
$\mathrm{~b}$ & 0.35 & 0.39 & 0.44 & 0.50 & 0.59 & 0.45 & 0.48 \\
$r^{2}$ & 0.77 & 0.78 & 0.83 & 0.85 & 0.90 & 0.82 & 0.85 \\
\cline { 2 - 8 } Time & 1.12 & 1.21 & 1.20 & 1.27 & 1.35 & 1.23 & 1.38 \\
\cline { 2 - 8 } & 2.17 & 1.84 & 1.86 & 1.70 & 1.68 & 1.91 & 1.63 \\
$I P$ & 2.85 & 2.59 & 2.27 & 2.01 & 1.70 & 2.24 & 2.09
\end{tabular}

Table 6: Summary of CHORD values for dragging experiment. Best and worst values are highlighted in green and gray respectively.

Error - Significant effect of CHORD on Error $\left(F_{6,451}=5.0\right.$, $p<.0001)$. Post hoc tests show: $\mathrm{TL}_{\mathrm{d}}$ caused more errors than $\mathrm{MR}_{\mathrm{d}}$ or $\mathrm{TI}_{\mathrm{d}}($ all $p<.001) ; \mathrm{TL}_{\mathrm{d}}$ and $\mathrm{RL}_{\mathrm{d}}$ caused more errors than $\mathrm{TI}_{\mathrm{d}}$ (resp. $p<.001$ and $p<.05$ ). Mean error rates all between $2.48 \%$ and $7.87 \%$. As expected, effects of TOLERANCE or AMPLITUDE on Error were significant.

Time - Significant effect of CHORD on Time $\left(F_{6,451}=7.3\right.$, $p<.0001)$. Post hoc tests show: $\mathrm{TR}_{\mathrm{d}}, \mathrm{TM}_{\mathrm{d}}, \mathrm{TI}_{\mathrm{d}}$ are faster than $\mathrm{RL}_{\mathrm{d}}, \mathrm{IM}_{\mathrm{d}}($ all $p<.05)$, all couples involving $\mathrm{RL}_{\mathrm{d}}$ or TId $p<.01)$; $\mathrm{TL}_{\mathrm{d}}$ is slower than $\mathrm{TI}_{\mathrm{d}}(p<.05)$. As expected, effects of TOLERANCE or AMPLITUDE on Time were significant.

Fitts' Law Modelling - All CHORD models have $r^{2}$ between .59 and .81 , see Table 3 for model parameters.

Throughput - Significant effect for CHORD on TP $\left(F_{6,451}=5.0, p<.0001\right)$. Post hoc tests show: $\mathrm{TI}_{\mathrm{d}}$ and $\mathrm{MR}_{\mathrm{d}}$ have higher $T P$ than $\mathrm{TL}_{\mathrm{d}}(p<.05)$; $\mathrm{TI}_{\mathrm{d}}$ has higher $T P$ than $\mathrm{TM}_{\mathrm{d}}$, $\mathrm{IM}_{\mathrm{d}}, \mathrm{RL}_{\mathrm{d}}$ and $\mathrm{TL}_{\mathrm{d}}(p<.05)$.

Ratings - Significant effects for CHORD on Ease-of-use, Speed, Accuracy, and Fatigue $\left(F_{6,66}>5.2, p<.001\right)$. Post hoc tests show a consistent general trend (all $p<.001$ ): $\mathrm{TI}_{\mathrm{d}}, \mathrm{IM}_{\mathrm{d}}$ and $\mathrm{MR}_{\mathrm{d}}$ are rated higher than $\mathrm{RL}_{\mathrm{d}}, \mathrm{TL}_{\mathrm{d}}$ and $\mathrm{TR}_{\mathrm{d}}$ (Ease-ofuse, Fatigue), $\mathrm{RL}_{\mathrm{d}}$ and $\mathrm{TL}_{\mathrm{d}}$ (Speed) and $\mathrm{TL}_{\mathrm{d}}$ (Accuracy).

\section{STUDY 2, EXPERIMENT 3: OBJECT SCALING}

The goal of this experiment is to measure the performance of different chords when scaling an object with direct manipulation. 12 participants were assigned to this experiment (7 females, mean age 23.6, SD 2.5). Refer to Study 2 for common apparatus, protocol, design, and analysis.

\section{Task}

The task required participants to scale an object using a specific two finger chord until it was within a target area (Figure 6). Participants were instructed to do this as fast as possible while maintaining a $4 \%$ error rate. Each trial began when both fingers touched a circular object. The object position was fixed and its diameter was 4,7 or $10 \mathrm{~cm}$ depending on zoom direction and TOLERANCE. The two fingers were spread or pinched without lifting, until the object border was contained within a ring-shaped target area (Figure 6). The trial ended when the object was released. If the any part of the object border was outside the target area on release, the trial was marked as an error and the display flashed orange.

\section{Design}

In this task, TOLERANCE corresponds to the outer target ring diameter divided by 2 (Figure 6c). AMPLITUDE corresponds (a)
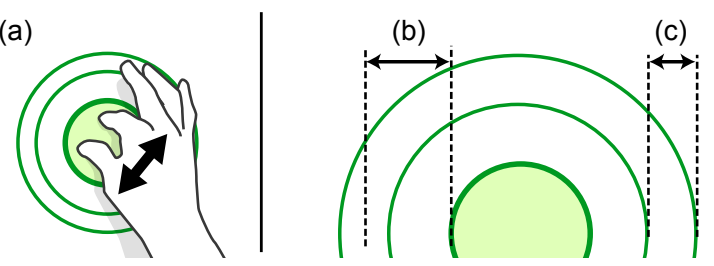

Figure 6: Scaling task. Chords are used to scale a circular object (shown in green here) until its outer edge is within a ring-shaped target area: (a) example using chord $\mathbf{T I}_{\mathbf{d}}$; (b) half of AMPLITUDE (c) TOLERANCE.

to the mean movement distance required by both fingers: twice the distance between the midpoint between the rings to the edge of the object (Figure $6 \mathrm{~b}$ ). Only the 4 'pinch' CHORDS were tested. TOLERANCES were $1,1.5$, and $2.0 \mathrm{~cm}$. AMPLITUDES were 3 and $6 \mathrm{~cm}$.

We use the standard Shannon formulation to calculate scaling ID rather than the one proposed by Zhao et al. [54]. This is because our scaling behaviour maps actual finger movement distance to the object scale (i.e. fingers are always the same distance from the outer edge of the object). Zhao et al. use the ratio of current and previous inter-finger distance for the object scale factor which leads to exponential growth and the extra logarithm terms in their ID formulation. Our approach aligns with Casiez et al.'s recommendation to control all performance studies in motor space [9] and our scaling behaviour is the same as previous work like Moscovich et al. [35]. The six combinations of TOLERANCE and AMPLITUDE generate IDs between 1.3 and 2.8 bits. The 6 REPETITIONS varied direction of scaling: scaling up and scaling down. In summary: 4 CONTACTS $\times 3$ BLOCKS $\times 3$ TOLERANCES $\times 2$ AMPLITUDES $\times 6$ REPETITIONS.

\section{Results}

As before, this section reports statistical tests and Fitts' Law modelling. Key values are summarized in Table 7, and trends for Throughput and Preference are summarized in Figure 8c in the Discussion section.

Fatigue or Learning - Significant effect for BLOCK on Time $\left(F_{2,22}=12.2, p<.001\right)$ but not Error. Post hoc tests show Block 1 is significantly slower than Blocks 2 and 3. Block 1 removed from subsequent analysis.

Error - No significant effect of CHORD on Error. Mean error rates all between $3.77 \%$ and $4.13 \%$. As expected, effects of TOLERANCE or AMPLITUDE on Error were significant.

Time - Significant effect for CHORD on Time $\left(F_{3,429}=4.2\right.$, $p<.01)$. Post hoc tests show: $\mathrm{TR}_{\mathrm{d}}$ is slower than all others except $\mathrm{TL}_{\mathrm{d}}($ all $p<.05)$. As expected, effects of TOLERANCE or AMPLITUDE on Time were significant.

Fitts' Law Modelling - All CHORD models have $r^{2} \geq .98$, see Table 7 for model parameters.

Throughput - No significant effect of CHORD.

Ratings - Significant effects for CHORD on Ease-of-use, Speed, Accuracy, and Fatigue $\left(F_{3,33}>9.7, p<.0001\right)$. Post hoc tests show a consistent general trend (all $p<.0001)$. $\mathrm{TI}_{\mathrm{d}}$ and 


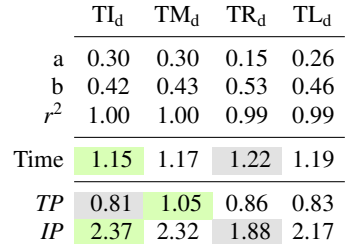

Table 7: Summary of CHORD values for scaling experiment. Best and worst values are highlighted in green and gray respectively.

$\mathrm{TM}_{\mathrm{d}}$ are rated higher than $\mathrm{TR}_{\mathrm{d}}$ and $\mathrm{TL}_{\mathrm{d}}$ (Ease-of-use, Speed) and $\mathrm{TL}_{\mathrm{d}}$ (Accuracy); $\mathrm{TI}_{\mathrm{d}}$ is rated higher than all other chords for Fatigue.

\section{STUDY 2, EXPERIMENT 4: OBJECT ROTATION}

The goal of this experiment is to measure the performance of different chords when rotating an object with direct manipulation. The same 12 participants who completed the scaling experiment were also assigned to this experiment ( 7 female, mean age 23.6, SD 2.5). The order of scaling and rotation experiments was counter-balanced. Refer to the Study 2 for common apparatus, protocol, design, and analysis.

\section{Task}

The task required participants to rotate an object until its angle aligned with a target. They did this as fast as possible using a specific two finger chord while maintaining an error rate around $4 \%$. Each trial two fingers touched the object which was fixed in position and always $8 \mathrm{~cm}$ in diameter. The object was rotated by twisting the fingers until a protruding key was within a pie-shaped target area (Figure 7). The trial ended when the object was released. If any part of the key was outside the target area when released, the trial was marked as an error and the display flashed orange. (a)

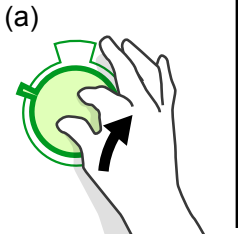

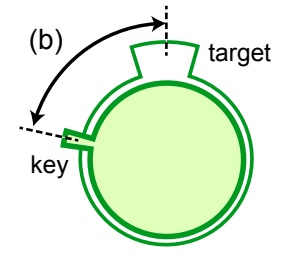

(c)

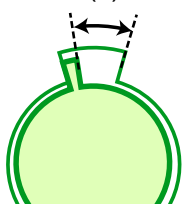

Figure 7: Rotating task. Participants used specific chords to rotate a circular object (shown in green here) until a key aligned with a target area: (a) example using chord $\mathbf{T I}_{\mathbf{d}}$; (b) AMPLITUDE; (c) TOLERANCE.

\section{Design}

In this task, TOLERANCE corresponds to the arc length of the target area less the aperture of the $5^{\circ}$ key (Figure $7 \mathrm{c}$ ). The AMPLITUDE corresponds to the angle between the bisector of the key and the bisector of the target area (Figure 7b).

All 7 CHORDS were tested. TOLERANCES were 5, 10, and $15^{\circ}$. AMPLITUDES were 25 and $90^{\circ}$. The six combinations of TOLERANCE and AMPLITUDE generate IDs between 1.4 and 4.2 bits. The 6 REPETITIONS varied direction of rotation: clockwise or counter-clockwise.

In summary: 7 CONTACTS $\times 3$ BLOCKS $\times 3$ TOLERANCES $\times 2$ AMPLITUDES $\times 6$ REPETITIONS.

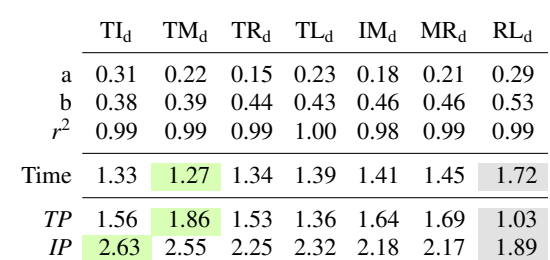

Table 8: Summary of CHORD values for rotating experiment. Best and worst values are highlighted in green and gray respectively.

\section{Results}

As before, this section reports statistical tests and Fitts' Law modelling. Key values are summarized in Table 8, and trends for Throughput and Preference are summarized in Figure $8 \mathrm{f}$ in the Discussion section.

Fatigue or Learning - A significant effect for BLOCK on Time $\left(F_{2,22}=4.5, p<.05\right)$ but not Error. BLOCK 1 is significantly slower than BLOCK 3 . Post hoc tests revealed that BLOCK 1 could not be discarded without discarding BLOCK 2 and also BLOCK 3. Therefore, all BLOCKS are used in subsequent analysis.

Error - Significant effect of CHORD on Error $\left(F_{6,451}=6.7\right.$, $p<.0001)$. Post hoc tests show: $\mathrm{MR}_{\mathrm{d}}$ has a lower error rate than $\mathrm{RL}_{\mathrm{d}}$ and $\mathrm{TL}_{\mathrm{d}}\left(p<.0001\right.$ and $p<.05$ resp.); $\mathrm{RL}_{\mathrm{d}}$ has a higher error rate than all except $\mathrm{TL}_{\mathrm{d}}($ all $p<.01)$. Mean error rates all between $2.29 \%$ and $7.54 \%$. As expected, effects of TOLERANCE or AMPLITUDE on Error were significant.

Time - Significant effect for CHORD on Time $\left(F_{6,451}=26.0\right.$, $p<.0001)$. Post hoc tests show: $\mathrm{TM}_{\mathrm{d}}$ is faster than all but $\mathrm{TR}_{\mathrm{d}}$ and $\mathrm{TI}_{\mathrm{d}}$ (all $p<.05$ ); $\mathrm{RL}_{\mathrm{d}}$ is slower than all others (all $p<.0001)$. As expected, effects of TOLERANCE or AMPLITUDE on Time were significant.

Fitts' Law Modelling - All CHORD models have $r^{2}$ between .97 and .98 , see Table 8 for model parameters.

Throughput - Significant effect for CHORD on TP $\left(F_{6,451}=21.0, p<.0001\right)$. Post hoc tests show: $\mathrm{RL}_{\mathrm{d}}$ has lower $T P$ than all $(p<.001) ; \mathrm{TM}_{\mathrm{d}}, \mathrm{TI}_{\mathrm{d}}$ and $\mathrm{TR}_{\mathrm{d}}$ have higher $T P$ than $\mathrm{TL}_{\mathrm{d}}$ and $\mathrm{RL}_{\mathrm{d}}(p<.05)$.

Ratings - Significant effects for CHORD on Ease-of-use, Speed, Accuracy, and Fatigue $\left(F_{6,66}>8.5, p<.0001\right)$. Post hoc tests show a consistent trend (all $p<.0001$ ): $\mathrm{TI}_{\mathrm{d}}, \mathrm{TM}_{\mathrm{d}}$ and $\mathrm{IM}_{\mathrm{d}}$ are rated higher than $\mathrm{TL}_{\mathrm{d}}$ and $\mathrm{RL}_{\mathrm{d}}$ for Ease-of-use, Speed, and Accuracy; $\mathrm{TI}_{\mathrm{d}}, \mathrm{IM}_{\mathrm{d}}$ and $\mathrm{TR}_{\mathrm{d}}$ are rated higher than $\mathrm{TL}_{\mathrm{d}}$ and $\mathrm{RL}_{\mathrm{d}}$ for Fatigue.

\begin{tabular}{llcc} 
& & \multicolumn{1}{c}{$\mathrm{C}_{\text {pref }}$} & \multicolumn{1}{c}{$\mathrm{C}_{\text {avoid }}$} \\
\cline { 2 - 4 } Pointing & FINGERS & $\mathrm{I}_{\mathrm{n}}, \mathrm{T}_{\mathrm{d}}, \mathrm{I}_{\mathrm{d}}, \mathrm{M}_{\mathrm{d}}$ & $\mathrm{L}_{\mathrm{n}}, \mathrm{R}_{\mathrm{n}}$ \\
& CHORDS & $\mathrm{TI}_{\mathrm{d}}, \mathrm{TM}_{\mathrm{d}}, \mathrm{IM}_{\mathrm{d}}, \mathrm{MR}_{\mathrm{d}}$ & $\mathrm{TR}_{\mathrm{d}}, \mathrm{TL}_{\mathrm{d}}, \mathrm{RL}_{\mathrm{d}}$ \\
\cline { 2 - 4 } Dragging & FINGERS & $\mathrm{I}_{\mathrm{n}}, \mathrm{T}_{\mathrm{d}}, \mathrm{I}_{\mathrm{d}}, \mathrm{M}_{\mathrm{d}}$ & $\mathrm{L}_{\mathrm{n}}, \mathrm{R}_{\mathrm{n}}, \mathrm{L}_{\mathrm{d}}$ \\
& CHORDS & $\mathrm{TI}_{\mathrm{d}}, \mathrm{IM}_{\mathrm{d}}, \mathrm{MR}_{\mathrm{d}}$ & $\mathrm{TL}_{\mathrm{d}}, \mathrm{RL}_{\mathrm{d}}, \mathrm{TR}_{\mathrm{d}}$ \\
\cline { 2 - 4 } Scaling & CHORDS & $\mathrm{TI}_{\mathrm{d}}$ & $\mathrm{TL}_{\mathrm{d}}$ \\
\cline { 2 - 4 } Rotation & CHORDS & $\mathrm{TI}_{\mathrm{d}}, \mathrm{TM}_{\mathrm{d}}, \mathrm{IM}_{\mathrm{d}}$ & $\mathrm{TL}_{\mathrm{d}}, \mathrm{RL}_{\mathrm{d}}$
\end{tabular}

Table 9: Recommendations of the CONTACTS to privilege $\left(\mathrm{C}_{\text {pref }}\right)$ and avoid $\left(\mathrm{C}_{\text {avoid }}\right)$. 
(a) pointing (fingers)

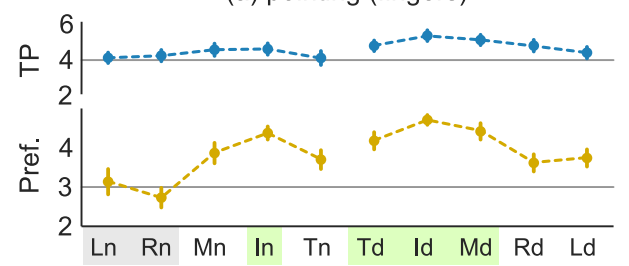

(d) dragging (fingers)

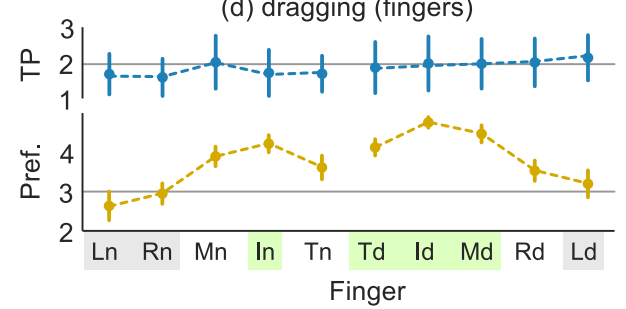

(b) pointing (chords)

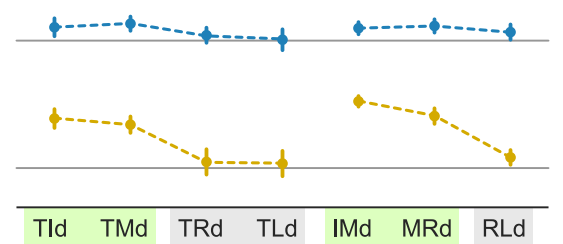

(e) dragging (chords)

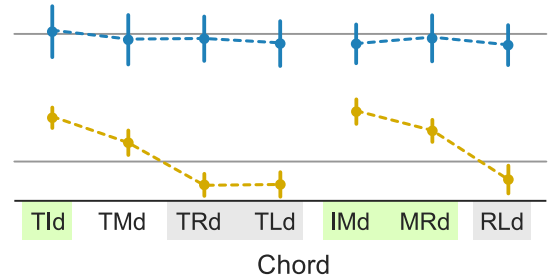

(c) scaling

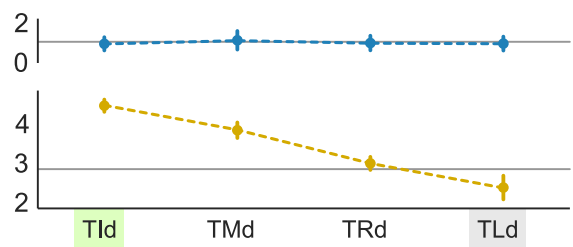

(f) rotation

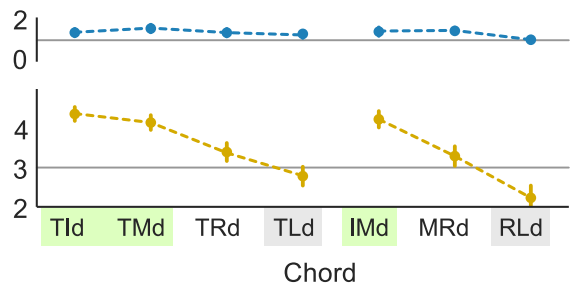

Figure 8: Task Throughput (bits/s) and mean Preference. All error bars indicate the $95 \% \mathrm{CI} \mathrm{C}_{\text {pref }}$ are highlighted in green and $\mathrm{C}_{\text {avoid }}$ in gray.

\section{DISCUSSION AND DESIGN APPLICATIONS}

Based on our results, we can provide guidelines for the development of finger identification interaction techniques that rely on the fundamental pointing, dragging, scaling, and rotation tasks. These recommendations are based on the analysis of both performance and preferences for each task.

We summarize our findings per task and CONTACT by forming three ranking groups: $\mathrm{C}_{\text {pref }}$ for fingers or chords to privilege, $\mathrm{C}_{\text {avoid }}$ for those to avoid, and $\mathrm{C}_{\text {other }}$ for those remaining. For each CONTACT and task, we computed a score based on the post hoc differences found for $T P$ and preference. Each CONTACT started with a score of 0 and we added 1 when it was significantly better and subtracted 1 when it was significantly worse. The ranking groups are based on the clusters this produced (summarized in Table 9 and Figure 8).

\section{Examples of design applications}

Pointing - Goguey et al. relied on a set of finger-dependent chords to activate quasi-modes and a set of fingers to trigger commands [17]. Following our recommendations, mode changes could be achieved using any chord since little to no precision is required. Triggering commands could be performed using $\mathrm{C}_{\text {pref }}$ when requiring precise location such as copy or paste $\mathrm{C}_{\text {other }}$ could be used for actions with low precision requirements such as select paragraph; and $\mathrm{C}_{\text {avoid }}$ could be used for non-contextual commands like save or to trigger quasi-mode constraining $\mathrm{C}_{\text {pref }}$ actions such as snapping when dragging or quantization when performing a rotation.

Dragging - Marqardt et al. mapped drawing tools to specific fingers and chords [31]. Our recommendations suggest that tools requiring precision - such as 1-finger pen or shape creation or shape positioning - should be mapped to $\mathrm{C}_{\text {pref }}$, tools requiring rough precision - such as 1 fingers interaction area creation or e.g. text boxes, or 2-finger panning - could be mapped to $\mathrm{C}_{\text {other }}$. $\mathrm{C}_{\text {avoid }}$ may be appropriate for low accuracy movements like swipes as suggested in [24], for example triggering non-contextual commands like flipping through drawing layers.
Scaling / Rotation - In a content manipulation application, object resizing/rotation and zooming could be achieved with the same gesture. Since resizing or rotation requires more control it would be preferable to map it to $\mathrm{C}_{\text {pref }}$ and possibly to two different chords - giving users more possibilities. Zooming or rotation of the view which requires rough precision could be mapped to $\mathrm{C}_{\text {other }}$.

\section{Extensions and Limitations}

Although we combine performance and preference to form recommendation groups, these qualities could be considered separately. For example, fingers and chords with high preference may be favoured for low-risk tasks, and fingers and chords with high performance for critical or irreversible commands. Our participants were primarily recruited from a university, a more diversified population could be examined using our methodology. Likewise, our results could be further validated by varying tablet position.

\section{CONCLUSION}

Exploiting finger identification for new types of multitouch interaction is an exciting direction for researchers and designers. However, there has been very little empirically-derived data for designers and researchers to justify which finger or chord is reasonable to use for given tasks. Our results and recommendations provided above are a significant step towards providing this missing data for the accuracy, performance, and preference for all fingers and primary dominant two finger chords when used for pointing, dragging, scaling, and rotation tasks. However, there is still work to be done. An obvious extension is to evaluate more combinations of chords, such as those using the non-dominant hand or with three or four contacts. Other factors can be explored, such as transition times between fingers and directional swipes independent of a marking menu task [24].

\section{ACKNOWLEDGMENTS}

This work was supported in part by Mitacs Globalink Research Award - Inria for research in Canada. 


\section{REFERENCES}

1. Apple Inc. Pages for iOS (iPad): Touchscreen basics. https://support . apple.com/kb/PH3571. Accessed: 2015-08-22.

2. Au, O. K.-C., and Tai, C.-L. Multitouch finger registration and its applications. In Proc. OZCHI (2010), 41-48.

3. Avery, J., Choi, M., Vogel, D., and Lank, E. Pinch-to-zoom-plus: An enhanced pinch-to-zoom that reduces clutching and panning. In Proc. UIST (2014), 595-604.

4. Azenkot, S., and Zhai, S. Touch behavior with different postures on soft smartphone keyboards. In Proc. MobileHCI (2012), 251-260.

5. Bachynskyi, M., Palmas, G., Oulasvirta, A., Steimle, J., and Weinkauf, T. Performance and ergonomics of touch surfaces: A comparative study using biomechanical simulation. In Proc. CHI (2015), 1817-1826.

6. Banovic, N., Li, F. C. Y., Dearman, D., Yatani, K., and Truong, K. N. Design of unimanual multi-finger pie menu interaction. In Proc. ITS (2011), 120-129.

7. Benko, H., Saponas, T. S., Morris, D., and Tan, D. Enhancing input on and above the interactive surface with muscle sensing. In Proc. ITS (2009), 93-100.

8. Bi, X., Li, Y., and Zhai, S. Ffitts law: Modeling finger touch with fitts' law. In Proc. CHI (2013), 1363-1372.

9. Casiez, G., and Roussel, N. No more bricolage!: Methods and tools to characterize, replicate and compare pointing transfer functions. In Proc. UIST (2011), 603-614.

10. Cockburn, A., Ahlström, D., and Gutwin, C. Understanding performance in touch selections: Tap, drag and radial pointing drag with finger, stylus and mouse. Int. J. Hum.-Comput. Stud. 70, 3 (Mar. 2012), 218-233.

11. Colle, H. A., and Hiszem, K. J. Standing at a kiosk: Effects of key size and spacing on touch screen numeric keypad performance and user preference. Ergonomics 47, 13 (2004), 1406-1423. PMID: 15513716.

12. Colley, A., and Häkkilä, J. Exploring finger specific touch screen interaction for mobile phone user interfaces. In Proc. OzCHI (2014), 539-548.

13. Ewerling, P., Kulik, A., and Froehlich, B. Finger and hand detection for multi-touch interfaces based on maximally stable extremal regions. In Proc. ITS (2012), 173-182.

14. Forlines, C., Wigdor, D., Shen, C., and Balakrishnan, R. Direct-touch vs. mouse input for tabletop displays. In Proc. CHI (2007), 647-656.

15. Ghomi, E., Huot, S., Bau, O., Beaudouin-Lafon, M., and Mackay, W. E. Arpège: Learning multitouch chord gestures vocabularies. In Proc. ITS (2013), 209-218.

16. Goguey, A., Casiez, G., Pietrzak, T., Vogel, D., and Roussel, N. Adoiraccourcix: Multi-touch Command Selection Using Finger Identification. In Proc. IHM (2014), 28-37.
17. Goguey, A., Casiez, G., Vogel, D., Chevalier, F., Pietrzak, T., and Roussel, N. A Three-step Interaction Pattern for Improving Discoverability in Finger Identification Techniques. In Proc. UIST Adjunct (2014), 33-34.

18. Gutwin, C., Cockburn, A., Scarr, J., Malacria, S., and Olson, S. C. Faster command selection on tablets with fasttap. In Proc. CHI (2014), 2617-2626.

19. Hall, A. D., Cunningham, J. B., Roache, R. P., and Cox, J. W. Factors affecting performance using touch-entry systems: Tactual recognition fields and system accuracy. Journal of applied psychology 73, 4 (1988), 711.

20. Hoggan, E., Williamson, J., Oulasvirta, A., Nacenta, M., Kristensson, P. O., and Lehtiö, A. Multi-touch rotation gestures: Performance and ergonomics. In Proc. CHI (2013), 3047-3050.

21. Holz, C., and Baudisch, P. Understanding touch. In Proc. CHI (2011), 2501-2510.

22. Holz, C., and Baudisch, P. Fiberio: A touchscreen that senses fingerprints. In Proc. UIST (2013), 41-50.

23. ISO, I. 9241-9 ergonomic requirements for office work with visual display terminals (vdts)-part 9:

Requirements for non-keyboard input devices (fdis-final draft international standard), 2000. International Organization for Standardization.

24. Lepinski, G. J., Grossman, T., and Fitzmaurice, G. The design and evaluation of multitouch marking menus. In Proc. CHI (2010), 2233-2242.

25. Ljubic, S., Glavinic, V., and Kukec, M. Finger-based pointing performance on mobile touchscreen devices: Fitts' law fits. In Universal Access in Human-Computer Interaction. Access to Today's Technologies, vol. 9175 of Lecture Notes in Computer Science, Springer International Publishing (2015), 318-329.

26. Luo, Y., and Vogel, D. Crossing-based Selection with Direct Touch Input. In Proc. CHI (2014), 2627-2636.

27. MacKenzie, I. S. A note on the information-theoretic basis for fitts' law. Journal of motor behavior 21, 3 (1989), 323-330.

28. MacKenzie, I. S. Fitts' law as a research and design tool in human-computer interaction. Hum.-Comput. Interact. 7, 1 (Mar. 1992), 91-139.

29. MacKenzie, I. S. A note on the validity of the shannon formulation for fitts' index of difficulty. Open Journal of Applied Sciences 3, 06 (2013), 360.

30. Malik, S., Ranjan, A., and Balakrishnan, R. Interacting with large displays from a distance with vision-tracked multi-finger gestural input. In Proc. UIST (2005), 43-52.

31. Marquardt, N., Kiemer, J., Ledo, D., Boring, S., and Greenberg, S. Designing user-, hand-, and handpart-aware tabletop interactions with the TouchID toolkit. In Proc. ITS (2011), 21-30.

32. McManus, I., Kemp, R., and Grant, J. Differences between fingers and hands in tapping ability: dissociation between speed and regularity. Cortex 22, 3 (1986), 461-473. 
33. Micire, M., Schedlbauer, M., and Yanco, H. Horizontal selection: An evaluation of a digital tabletop input device. In Proc. AMCIS (2007), 164.

34. Möllers, M., Dumont, N., Ladwig, S., and Borchers, J. Improving touch accuracy on large tabletops using predecessor and successor. In Proc. CHI (2013), 755-758.

35. Moscovich, T., and Hughes, J. F. Multi-finger cursor techniques. In Proc. GI (2006), 1-7.

36. Murugappan, S., Vinayak, Elmqvist, N., and Ramani, K. Extended multitouch: recovering touch posture and differentiating users using a depth camera. In Proc. UIST (2012), 487-496.

37. Ng, A., Brewster, S. A., and Williamson, J. H. Investigating the effects of encumbrance on one- and two- handed interactions with mobile devices. In Proc. CHI (2014), 1981-1990.

38. Ng, A., Lepinski, J., Wigdor, D., Sanders, S., and Dietz, P. Designing for low-latency direct-touch input. In Proc. UIST (2012), 453-464.

39. Parhi, P., Karlson, A. K., and Bederson, B. B. Target size study for one-handed thumb use on small touchscreen devices. In Proc. MobileHCI (2006), 203-210.

40. Park, Y. S., and Han, S. H. One-handed thumb interaction of mobile devices from the input accuracy perspective. International Journal of Industrial Ergonomics 40, 6 (2010), 746-756.

41. Perry, K. B., and Hourcade, J. P. Evaluating one handed thumb tapping on mobile touchscreen devices. In Proc. GI (2008), 57-64.

42. Po, B. A., Fisher, B. D., and Booth, K. S. Mouse and touchscreen selection in the upper and lower visual fields. In Proc. CHI (2004), 359-366.

43. Potter, R. L., Weldon, L. J., and Shneiderman, B. Improving the accuracy of touch screens: an experimental evaluation of three strategies. In Proc. of the SIGCHI conference on Human factors in computing systems (1988), 27-32.

44. Roy, Q., Guiard, Y., Bailly, G., Lecolinet, E., and Rioul, O. Glass+skin: An empirical evaluation of the added value of finger identification to basic single-touch interaction on touch screens. In Proc. INTERACT (2015), 55-71.

45. Sasangohar, F., MacKenzie, I. S., and Scott, S. D. Evaluation of mouse and touch input for a tabletop display using fitts' reciprocal tapping task. In Proc. HFES (2009), 839-843.

46. Scott MacKenzie, I. Fitts' throughput and the remarkable case of touch-based target selection. In Human-Computer Interaction: Interaction Technologies, M. Kurosu, Ed., vol. 9170 of Lecture Notes in Computer Science, Springer International Publishing (2015), 238-249.

47. Sears, A., and Shneiderman, B. High precision touchscreens: Design strategies and comparisons with a mouse. Int. J. Man-Mach. Stud. 34, 4 (Apr. 1991), 593-613.

48. Sugiura, A., and Koseki, Y. A user interface using fingerprint recognition: holding commands and data objects on fingers. In Proc. UIST (1998), 71-79.

49. Vega, K., and Fuks, H. Beauty tech nails: Interactive technology at your fingertips. In Proc. TEI, ACM (2013), 61-64.

50. Wagner, J., Lecolinet, E., and Selker, T. Multi-finger chords for hand-held tablets: Recognizable and memorable. In Proc. CHI (2014), 2883-2892.

51. Wang, F., and Ren, X. Empirical Evaluation for Finger Input Properties in Multi-touch Interaction. In Proc. CHI (2009), 1063-1072.

52. Wang, J., and Canny, J. FingerSense: augmenting expressiveness to physical pushing button by fingertip identification. In CHI EA (2004), 1267-1270.

53. Westerman, W. Hand tracking, finger identification, and chordic manipulation on a multi-touch surface. $\mathrm{PhD}$ thesis, University of Delaware, 1999.

54. Zhao, J., Soukoreff, R. W., and Balakrishnan, R. Exploring and modeling unimanual object manipulation on multi-touch displays. International Journal of Human-Computer Studies 78, 0 (2015), 68 - 80. 